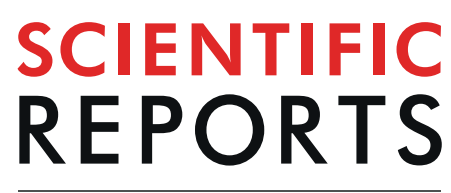

natureresearch

Check for updates

\title{
Age-independent increasing prevalence of Human Papillomavirus-driven oropharyngeal carcinomas in North-East Italy
}

\author{
Annarosa Del Mistro ${ }^{\circledR}$, Helena Frayle ${ }^{1}$, Anna Menegaldo ${ }^{2}$, Niccolò Favaretto ${ }^{3}$, Silvia Gori ${ }^{1}$, \\ Piero Nicolai ${ }^{3}$, Giacomo Spinato 2,4 , Salvatore Romeo ${ }^{5}$, Giancarlo Tirelli, , Maria Cristina da Mosto ${ }^{2}$, \\ Jerry Polesel ${ }^{7} \&$ Paolo Boscolo Rizzo ${ }^{2}$
}

HPV-driven oropharyngeal carcinomas (OPCs) show geographical variations with increasing temporal trends in several areas. We investigated their frequency and clinical outcomes within a prospective multicenter cohort study in North-East Italy. A tumor was defined as HPV-driven by using at least two different biomarkers, usually HPV-DNA positivity and $\mathrm{p} 16^{1 \mathrm{NK} 4 \mathrm{~A}}$ overexpression. Different survival outcomes were compared among patients with HPV-driven and non-HPV-driven tumors. Overall, 42/130 (32.3\%) patients with newly diagnosed OPC during the period 2000-2018 resulted HPV-driven; HPV16 was involved in 37 cases (88\%), HPV33 in 3 cases (7\%), HPV58 and HPV18 in 1 case each. Over time, HPV-driven cases raised from 16.7\% (6/36) during 2000-2006 to 46.1\% (24/52) during 2013-2018 $(p<0.001)$. The increase in HPV-driven OPCs was more marked in females than males $(p=0.010)$, and the frequency of HPV-driven cases was similar in the different age groups. In comparison to cases with non-HPV-driven tumors, a significantly $(p<0.001)$ better progression-free and overall survival were recorded among patients affected by HPV-driven OPC. The prevalence of HPV-driven OPC cases has been significantly increasing during the last two decades also in North-East Italy and was associated with favorable outcome. OPCs driven by non-HPV16 oncogenic types were restricted to patients older than 68-yrs.

Oropharyngeal squamous cell carcinomas (OPC) are causally associated to chemical exposure (tobacco smoking and/or alcohol) or persistent infection by high-risk HPV (human papillomavirus) types ${ }^{1,2}$. In comparison to chemical-induced tumors, HPV-driven cancers represent a separate entity, characterized by a distinct molecular pathway, a better response to treatment and an improved prognosis ${ }^{3}$. In particular, patients with HPV-driven OPC show good response to chemotherapy and radiotherapy with a good control of loco-regional relapse, but not of distant metastases. Among the factors influencing the prognosis, stage and smoking habit are well recognized $^{4,5}$, while studies on the search for biomarkers able to predict patients' risk of relapse are ongoing ${ }^{6}$.

Large variations on the frequency of HPV-driven OPC in different geographic areas exist, with highest (50$60 \%$ ) figures in United States, Canada and Northern Europe, and lower in Southern Europe including Italy; in this latter the frequency is around $25-30 \%^{7}$. In particular, within Europe the frequency was reported to range

${ }^{1}$ Immunology and Diagnostic Molecular Oncology Unit, Veneto Institute of Oncology IOV - IRCCS, Via Gattamelata, 64, 35128, Padova, Italy. ${ }^{2}$ Department of Neurosciences DNS, Section of Otolaryngology, University of Padova, P. le Ospedale 1, 31100, Treviso, Italy. ${ }^{3}$ Department of Neurosciences DNS, Section of Otolaryngology, University of Padova, Via Giustiniani 2, 35128, Padova, Italy. ${ }^{4}$ Department of Surgery, Oncology and Gastroenterology, Section of Oncology and Immunology, University of Padova, Via Gattamelata, 64, 35128, Padova, Italy. ${ }^{5}$ Anatomical Pathology Unit, San Donà di Piave Hospital, Azienda ULSS 4 Veneto Orientale, Via Nazario Sauro 25, 30027, San Donà di Piave, VE, Italy. ${ }^{6}$ Head and Neck Department, Cattinara Hospital, University of Trieste, Strada di Fiume 447, 34149, Trieste, Italy. ${ }^{7}$ Unit of Cancer Epidemiology, Aviano National Cancer Institute, IRCCS, Via Franco Gallini, 2, 33081, Aviano, PN,

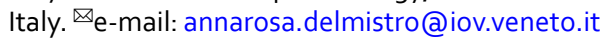




\begin{tabular}{|c|c|c|c|c|}
\hline & \multirow{2}{*}{\begin{tabular}{|l|}
$\begin{array}{l}\text { Total } \\
\text { patients }\end{array}$ \\
$\mathbf{n}$ \\
\end{tabular}} & \multicolumn{2}{|c|}{$\begin{array}{l}\text { HPV-driven } \\
\text { cancers }\end{array}$} & \multirow[b]{2}{*}{$\mathrm{CMH}_{\text {test }}{ }^{\mathrm{a}}$} \\
\hline & & $\mathbf{n}$ & $(\%)$ & \\
\hline \multicolumn{5}{|l|}{ Gender } \\
\hline Female & 35 & 18 & $(51.4)$ & \\
\hline Male & 95 & 24 & $(25.3)$ & $\mathrm{p}=0.005$ \\
\hline \multicolumn{5}{|l|}{ Age (years) } \\
\hline$<65$ & 68 & 21 & $(30.9)$ & \\
\hline$\geq 65$ & 62 & 21 & $(33.9)$ & $\mathrm{p}=0.717$ \\
\hline \multicolumn{5}{|l|}{ Year of diagnosis } \\
\hline $2000-2006$ & 36 & 6 & $(16.7)$ & \\
\hline $2007-2012$ & 42 & 12 & $(28.6)$ & \\
\hline 2013-2018 & 52 & 24 & $(46.2)$ & $\mathrm{p}<0.001$ \\
\hline \multicolumn{5}{|l|}{ Cancer subsite } \\
\hline Base of tongue & 28 & 11 & $(39.3)$ & \\
\hline Tonsil & 84 & 30 & $(35.7)$ & \\
\hline Other & 18 & 1 & $(5.6)$ & $\mathrm{p}=0.021^{\mathrm{c}}$ \\
\hline \multicolumn{5}{|l|}{ TNM stage (7th ed.) } \\
\hline I-II & 13 & 3 & $(23.1)$ & \\
\hline III & 23 & 11 & $(47.8)$ & \\
\hline IV & 94 & 28 & $(29.8)$ & $\mathrm{p}=0.995$ \\
\hline \multicolumn{5}{|l|}{ TNM stage (8th ed.) } \\
\hline I-II & 38 & 27 & $(71.1)$ & \\
\hline III & 27 & 15 & $(55.6)$ & \\
\hline IV & 65 & 0 & $(0.0)$ & $\mathrm{p}<0.001$ \\
\hline \multicolumn{5}{|l|}{ Grading } \\
\hline Well differentiated & 10 & 2 & $(20.0)$ & \\
\hline Moderately differentiated & 53 & 13 & $(24.5)$ & \\
\hline Poorly differentiated & 55 & 20 & $(36.4)$ & $\mathrm{p}=0.143$ \\
\hline Unknown & 12 & 6 & $(50.0)$ & \\
\hline \multicolumn{5}{|l|}{ Tobacco smoking } \\
\hline Never & 26 & 18 & $(69.2)$ & \\
\hline Former & 30 & 10 & $(33.3)$ & \\
\hline Current & 74 & 14 & $(18.9)$ & $\mathrm{p}<0.001^{\mathrm{c}}$ \\
\hline \multicolumn{5}{|l|}{ Alcohol drinking ${ }^{b}$} \\
\hline Never & 54 & 30 & $(55.6)$ & \\
\hline Former & 13 & 1 & $(7.7)$ & \\
\hline Current & 61 & 10 & $(16.4)$ & $\mathrm{p}<0.001^{\mathrm{c}}$ \\
\hline
\end{tabular}

Table 1. Distribution of 130 patients with oropharyngeal carcinomas according to socio-demographic and clinical characteristics. ${ }^{\mathrm{a} C o c h r a n-M a n t e l-H a e n s z e l ~ t e s t ; ~}{ }^{\mathrm{b}}$ Two patients did not report drinking habits; ${ }^{\mathrm{c}}$ Fisher exact test.

from $24.2 \%$ to $56.5 \%$ in Southern and Northern countries, respectively ${ }^{8}$. Data on HPV prevalence in OPC cases showing differences among Italian regions have also been reported, with figures ranging from $11 \%$ to $75 \%{ }^{9-12}$; small groups of patients were included and different HPV detection methods were used.

In most areas the incidence of HPV-driven OPC is on the rise, a trend more pronounced in the countries with higher frequencies ${ }^{2,13,14}$.

The improved prognosis of HPV-driven OPC has prompted investigations on aspects such as the best strategy to correctly distinguish HPV-driven from non-HPV-driven cases $^{15}$, predictive biomarkers of relapse $\mathrm{e}^{5}$, and possible modifications of the therapeutic regimens to reduce correlated morbidity ${ }^{16}$.

The present study reports a time-trend analysis of HPV-driven cases over roughly two decades and analyzes the clinical outcome in relation to viral and cellular parameters.

\section{Results}

A total of 130 patients with primary OPC (median age: 65 years; range $41-85$ years), were included in the study; they were predominantly males, no peak age at diagnosis was observed, and the tonsil was the most frequently involved sub-site. Anatomo-clinical data are summarized in Table 1.

Frequency and characteristics of HPV-driven tumors. Overall, 42/130 (32.3\%) cases resulted HPV-driven (Table 1); prevalence was higher among never smokers and never drinkers $(\mathrm{p}<0.001)$, and among 


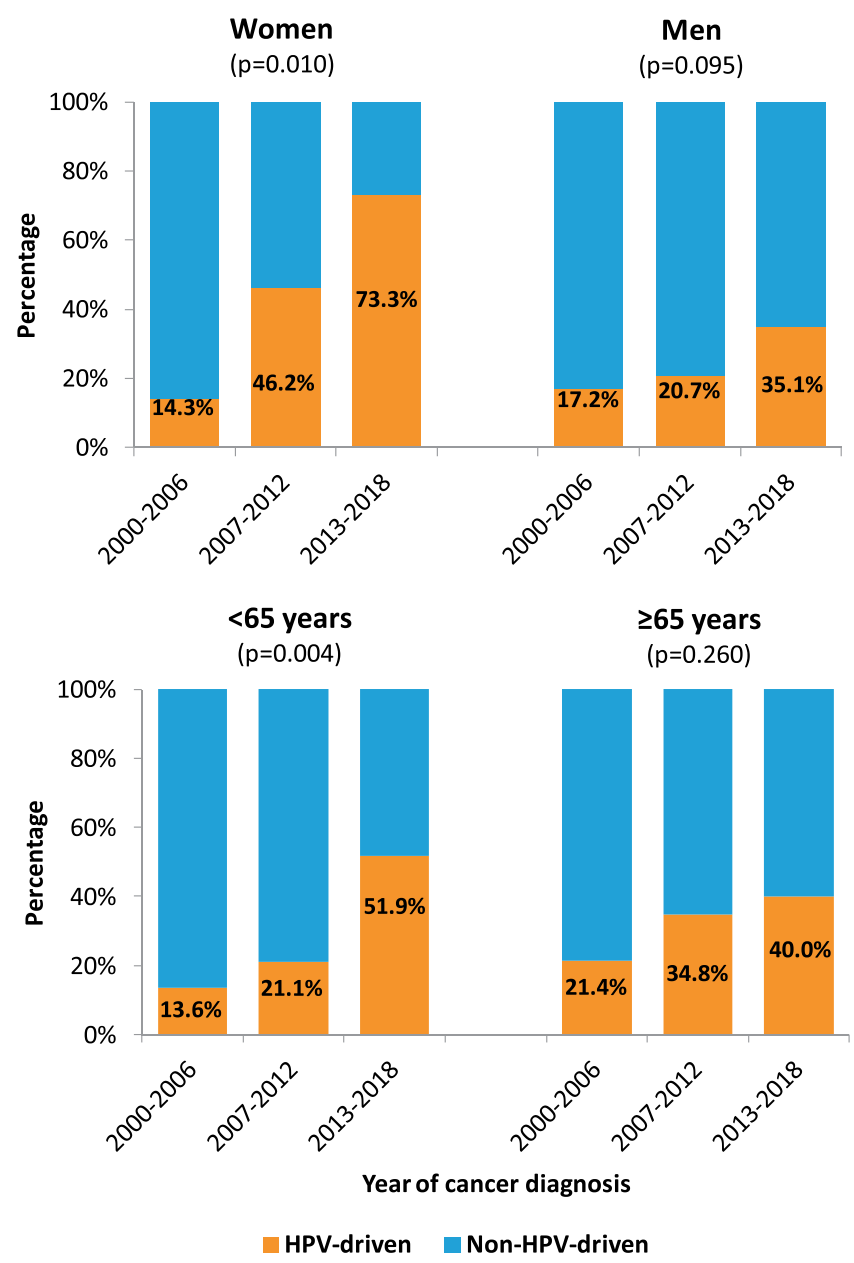

Figure 1. Prevalence of HPV-driven OPC by gender, age and year of diagnosis. OPC cases are grouped in three periods and the proportions of HPV-driven over total cases are shown.

women than among men $(51.4 \%$ vs. $25.3 \%$; $\mathrm{p}=0.005)$ with a male/female prevalence ratio of 0.49 (95\% CI: 0.21-0.69). Conversely, patients' age at diagnosis was similar to that of non-HPV-driven cases.

A statistically significant increase over time was recorded; HPV-driven cases raised from $16.7 \%(6 / 36)$ during 2000-2006 to 46.1\% (24/52) during 2013-2018 ( $<<0.001$; Table 1). By stratifying for gender and median age, the increasing trend was evident in both genders, more pronounced and significant in female $(\mathrm{p}=0.010)$ and in younger patients $(\mathrm{p}=0.004$; Fig. 1). HPV16 was involved in 37 cases $(88 \%)$, HPV33 in 3 (7\%) and HPV58 and HPV 18 in 1 case each. HPV16 was more frequently detected among younger patients (median 62 years, range 41-83), whereas other types were identified only among older patients (median 78 years, range 69-84) $(\mathrm{p}=0.004)$. A box plot of age for HPV-negative, HPV16-positive and HPVno16-positive cases is reported in Fig. 2. For HPV-driven cases, the differences between patients with HPV16-driven OPC and patients with other hrHPV types are summarized in Table 2.

Viral load was analyzed by real-time PCR, and a valid result is available for 36/37 HPV16-driven tumors; a median of 123,5 HPV 16 copies/cell (range 1,3-1375; >100 in 50\%) was detected.

No correlations with socio-demographic and clinical characteristics emerged (Supplementary Table 1).

The HPV-driven status was determined by HPV-DNA positivity and p16 overexpression in 30 cases, HPV-DNA positivity and positivity for E6-mRNA and/or E6 oncoprotein and/or anti-E6/E7 antibodies in 5 cases, and HPV-DNA positivity and high HPV16 viral load (median 297,2 copies/cell) in 7 cases. HPV16 DNA was detected at low viral load (2 copies/cell) in one p16-negative, non-HPV-driven case.

The expression of p16 protein was evaluated in 66 cases (30 HPV-driven and 36 non-HPV-driven). Overexpression was recorded in all HPV-driven and in 5/36 (13,9\%) non-HPV-driven tumors tested (Supplementary Table 2). The remaining $12 \mathrm{HPV}$-driven cases not analysed for p16 were mainly diagnosed in the 2000-2006 period, when p16 analysis was not routinely performed.

Clinical outcome. Overall, by 31 July 2019 (median follow-up length: 33 months, Q1-Q3: 14-60 months) death occurred in 70/130 (53.8\%) patients; 8/42 (19.0\%) of HPV-driven and 62/88 (70.4\%) of non-HPV-driven cases, respectively.

Different socio-demographic and clinical characteristics were evaluated and correlated with clinical outcome (Table 3). TNM (Tumor Nodes Metastases) stage as defined in the 8th edition was statistically correlated 


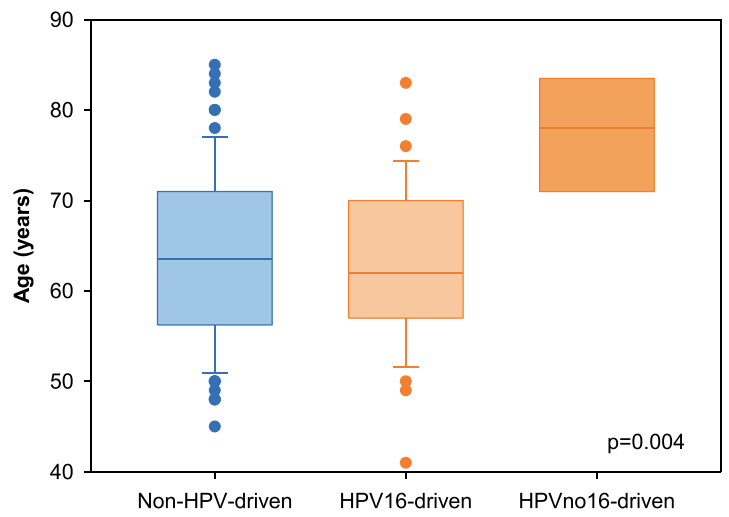

Figure 2. Box plot analysis of age at diagnosis of patients with non-HPV-driven and HPV-driven (HPV16 or other hrHPV types) OPC.

\begin{tabular}{|c|c|c|c|}
\hline & $\begin{array}{l}\text { HPV16+ } \\
\mathrm{N}=37\end{array}$ & $\begin{array}{l}\text { HPVno16+ } \\
\mathrm{N}=5\end{array}$ & $\begin{array}{l}\text { Fisher exact } \\
\text { test }\end{array}$ \\
\hline \multicolumn{4}{|l|}{ Gender } \\
\hline Female & 16 & 2 & $\mathrm{p}=1.000$ \\
\hline Male & 21 & 3 & \\
\hline $\mathrm{M} / \mathrm{F}$ ratio & 1,3 & 1,5 & \\
\hline \multicolumn{4}{|l|}{ Age (years) } \\
\hline Median & 62 & 78 & $\mathrm{p}=0.004^{\mathrm{a}}$ \\
\hline Range & $41-83$ & $69-84$ & \\
\hline \multicolumn{4}{|l|}{ Year of diagnosis } \\
\hline $2000-2006$ & $6(100 \%)$ & $0(0 \%)$ & $\mathrm{p}=0.672$ \\
\hline $2007-2012$ & $11(92 \%)$ & $1(8 \%)$ & \\
\hline 2013-2018 & $20(83 \%)$ & $4(17 \%)$ & \\
\hline \multicolumn{4}{|l|}{ Cancer subsite } \\
\hline Tonsil & $28(76 \%)$ & $3(60 \%)$ & $\mathrm{p}=0.131$ \\
\hline Base of tongue & 9 & 2 & \\
\hline \multicolumn{4}{|l|}{ TNM stage (8th ed.) } \\
\hline I-II & $23(62 \%)$ & $4(80 \%)$ & $\mathrm{p}=0.639$ \\
\hline III-IV & 14 & 1 & \\
\hline \multicolumn{4}{|l|}{ Tobacco smoking } \\
\hline Never & $17(46 \%)$ & $1(20 \%)$ & $\mathrm{p}=0.501$ \\
\hline \multicolumn{4}{|l|}{ Alcohol drinking } \\
\hline Never & $26(70 \%)$ & $4(80 \%)$ & $\mathrm{p}=1.000$ \\
\hline \multicolumn{4}{|l|}{ Clinical outcome } \\
\hline Complete remission & $34(92 \%)$ & $5(100 \%)$ & \\
\hline OS status: 1 & 8 & 0 & \\
\hline PFS status: 1 & 9 & 0 & \\
\hline Exitus: 1 & 8 & 0 & \\
\hline
\end{tabular}

Table 2. HPV-driven OPC cases: anatomo-clinical differences by viral type. HPVno16+ cases = HPV types 33 (3 cases), 18 and 58 ( 1 case each). ${ }^{a}$ Wilcoxon test.

with progression-free (PFS) and overall (OS) survival; PFS hazard ratios (HR) for stages III and IV were 2.82 and 4.65, respectively; the corresponding HRs for OS were 2.62 and 3.53, respectively. A significant correlation was also found between current alcohol drinking and both PFS and OS (HR 2.59 and 3.18, respectively). Among HPV-driven cases, a significantly better control of mucosal $(p=0.003)$ and regional $(p=0.006)$ relapse and of second primary tumor $(\mathrm{p}=0.009)$ was recorded, whereas a not significant difference $(\mathrm{p}=0.360)$ for distant control was observed (Table 4); PFS and OS were highly significantly $(\mathrm{p}<0.001)$ improved (Fig. 3 ). Four out of five patients with p16 positive/HPV-DNA negative tumors showed an unfavorable outcome (Supplementary Table 2). 


\begin{tabular}{|c|c|c|c|c|c|c|c|c|c|}
\hline & \multirow[b]{2}{*}{ Pts } & \multicolumn{4}{|c|}{ Progression-free survival $^{\mathrm{b}}$} & \multicolumn{4}{|c|}{ Overall survival } \\
\hline & & $\mathbf{n}$ & $(\%)$ & HR & $(95 \% \mathrm{CI})$ & $\mathbf{n}$ & $(\%)$ & HR & $(95 \% \mathrm{CI})$ \\
\hline \multicolumn{10}{|l|}{ Gender } \\
\hline Female & 35 & 16 & $(45.7)$ & & Ref. & 15 & $(42.9)$ & & Ref. \\
\hline Male & 95 & 63 & $(66.3)$ & 0.86 & $(0.47-1.56)$ & 60 & $(63.2)$ & 0.76 & $(0.41-1.41)$ \\
\hline \multicolumn{10}{|l|}{ Age (years) } \\
\hline$<65$ & 68 & 42 & $(61.8)$ & & Ref. & 39 & $(57.4)$ & & Ref. \\
\hline$\geq 65$ & 62 & 37 & $(59.7)$ & 1.33 & $(0.83-2.11)$ & 36 & $(58.1)$ & 1.60 & $(0.99-2.59)$ \\
\hline \multicolumn{10}{|c|}{ Year of diagnosis } \\
\hline $2000-2006$ & 36 & 28 & $(77.8)$ & & Ref & 28 & $(77.8)$ & & Ref \\
\hline $2007-2012$ & 42 & 33 & $(78.6)$ & 1.84 & $(1.05-3.23)$ & 30 & $(71.4)$ & 1.41 & $(0.80-2.49)$ \\
\hline $2013-2018$ & 52 & 18 & $(34.6)$ & 0.83 & $(0.44-1.55)$ & 17 & $(32.7)$ & 0.90 & $(0.47-1.72)$ \\
\hline \multicolumn{10}{|l|}{ Cancer subsite } \\
\hline Base of tongue & 28 & 11 & $(39.3)$ & & Ref. & 10 & $(35.7)$ & & Ref. \\
\hline Tonsil & 84 & 57 & $(67.9)$ & 1.09 & $(0.53-2.24)$ & 54 & $(64.3)$ & 1.09 & $(0.52-2.27)$ \\
\hline Other & 18 & 11 & $(61.1)$ & 1.02 & $(0.41-2.56)$ & 11 & $(61.1)$ & 1.15 & $(0.46-2.89)$ \\
\hline \multicolumn{10}{|c|}{ TNM stage $(7 \text { th ed. })^{c}$} \\
\hline I-II & 13 & 7 & $(53.9)$ & & Ref. & 7 & $(53.9)$ & & Ref. \\
\hline III & 23 & 14 & $(60.9)$ & 1.35 & $(0.53-3.42)$ & 14 & $(60.9)$ & 1.49 & $(0.59-3.80)$ \\
\hline IV & 94 & 58 & $(61.7)$ & 1.89 & $(0.83-4.28)$ & 54 & $(57.5)$ & 1.81 & $(0.80-4.12)$ \\
\hline \multicolumn{10}{|c|}{ TNM stage (8th ed.) } \\
\hline I-II & 38 & 12 & $(31.6)$ & & Ref. & 12 & $(31.6)$ & & Ref. \\
\hline III & 27 & 17 & $(63.0)$ & 2.82 & $(1.29-6.18)$ & 16 & $(59.3)$ & 2.62 & $(1.19-5.76)$ \\
\hline IV & 65 & 50 & $(76.9)$ & 4.65 & $(2.27-9.49)$ & 47 & $(72.3)$ & 3.53 & $(1.76-7.09)$ \\
\hline \multicolumn{10}{|l|}{ Grading } \\
\hline G1-G2 & 63 & 48 & $(76.2)$ & & Ref. & 45 & $(71.4)$ & & Ref. \\
\hline G3 & 55 & 28 & $(50.9)$ & 0.57 & $(0.57-0.95)$ & 27 & $(49.1)$ & 0.79 & $(0.47-1.34)$ \\
\hline \multicolumn{10}{|c|}{ Tobacco smoking } \\
\hline Never & 26 & 11 & $(42.3)$ & & Ref. & 10 & $(38.5)$ & & Ref. \\
\hline Former & 30 & 19 & $(63.3)$ & 1.11 & $(0.49-2.55)$ & 18 & $(60.0)$ & 0.99 & $(0.42-2.31)$ \\
\hline Current & 74 & 49 & $(66.2)$ & 1.12 & $(0.52-2.41)$ & 47 & $(63.5)$ & 1.27 & $(0.58-2.79)$ \\
\hline \multicolumn{10}{|c|}{ Alcohol drinking } \\
\hline Never & 54 & 18 & $(33.3)$ & & Ref. & 17 & $(31.5)$ & & Ref. \\
\hline Former & 13 & 10 & $(76.9)$ & 1.68 & $(0.75-3.80)$ & 9 & $(69.2)$ & 1.93 & $(0.82-4.54)$ \\
\hline Current & 61 & 50 & $(82.0)$ & 2.59 & $(1.45-4.64)$ & 48 & $(78.7)$ & 3.18 & $(1.74-5.79)$ \\
\hline
\end{tabular}

Table 3. Hazard ratio (HR) and corresponding $95 \%$ confidence interval $(\mathrm{CI})^{\mathrm{a}}$ for progression-free survival and

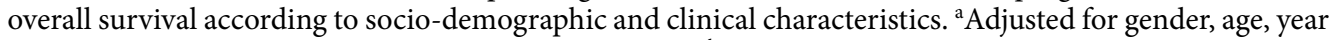
of diagnosis, TNM stage (8th ed.), and alcohol drinking. ${ }^{\mathrm{b}}$ One patient was not evaluable for progression-free survival. ${ }^{\mathrm{c}}$ Adjusted for gender, age, year of diagnosis, and alcohol drinking.

\begin{tabular}{|c|c|c|c|c|}
\hline \multirow[b]{2}{*}{ Survival outcome } & \multicolumn{2}{|c|}{ Crude estimates $^{\mathrm{a}}$} & \multicolumn{2}{|c|}{$\begin{array}{l}\text { Adjusted } \\
\text { estimates }^{\mathrm{b}}\end{array}$} \\
\hline & HR & $(95 \% \mathrm{CI})$ & HR & $(95 \% \mathrm{CI})$ \\
\hline Mucosal control & 0.10 & $(0.02-0.44)$ & 0.14 & $(0.03-0.61)$ \\
\hline Regional control & 0.18 & $(0.05-0.60)$ & 0.28 & $(0.08-1.02)$ \\
\hline Locoregional control & 0.11 & $(0.03-0.36)$ & 0.16 & $(0.05-0.52)$ \\
\hline Distant control & 0.66 & $(0.16-2.67)$ & 1.64 & $(0.31-8.72)$ \\
\hline SPT $_{\text {control }}{ }^{\mathrm{c}}$ & 0.09 & $(0.01-0.70)$ & 0.10 & $(0.01-0.83)$ \\
\hline Progression-free survival & 0.22 & $(0.11-0.42)$ & 0.27 & $(0.13-0.54)$ \\
\hline Overall survival & 0.25 & $(0.12-0.49)$ & 0.33 & $(0.16-0.67)$ \\
\hline
\end{tabular}

Table 4. Hazard ratio (HR) and corresponding 95\% confidence interval (CI) for HPV-driven tumors vs nonHPV-driven tumors. SPT: second primary tumor a Adjusted for gender, age and year of diagnosis. ${ }^{b}$ Further adjusted for T status, $\mathrm{N}$ status, and alcohol drinking. 'Including only cancer of the head and neck, oesophagus and lung. 
Mucosal control
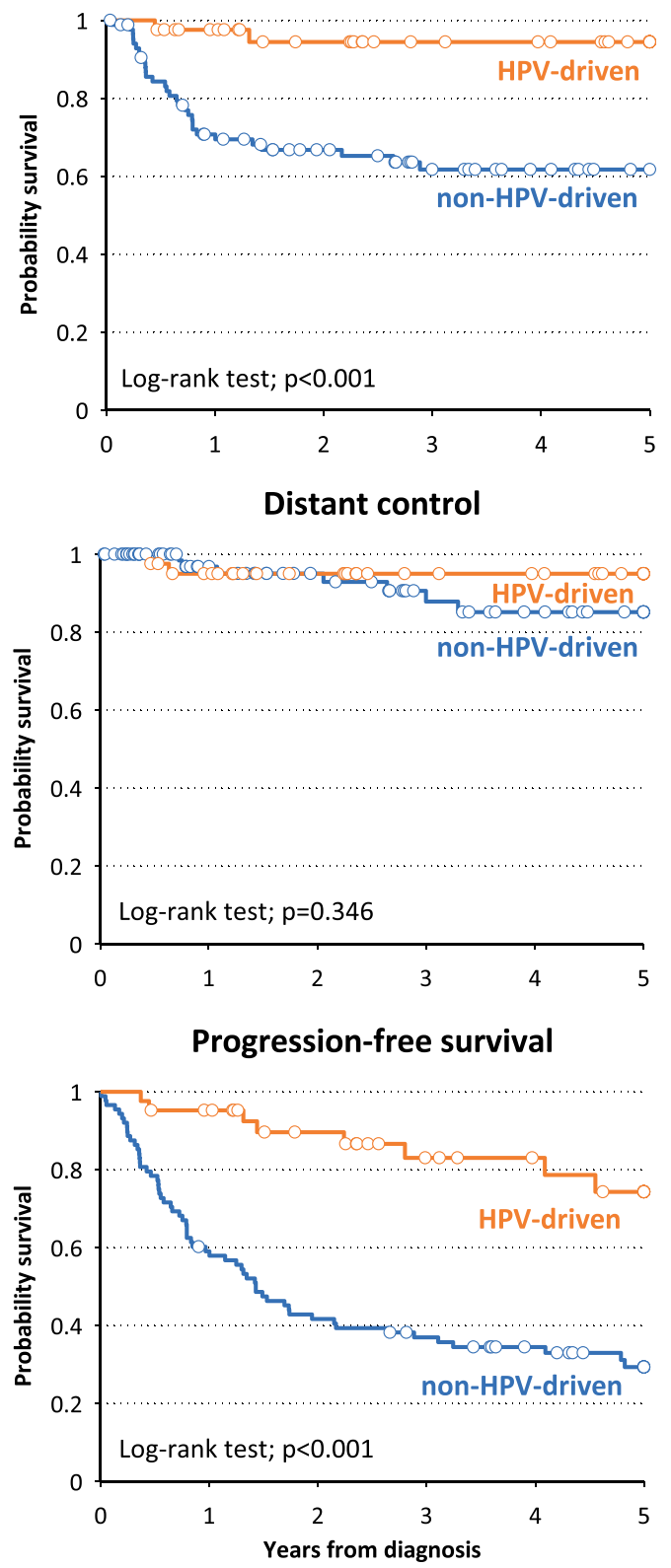

Regional control
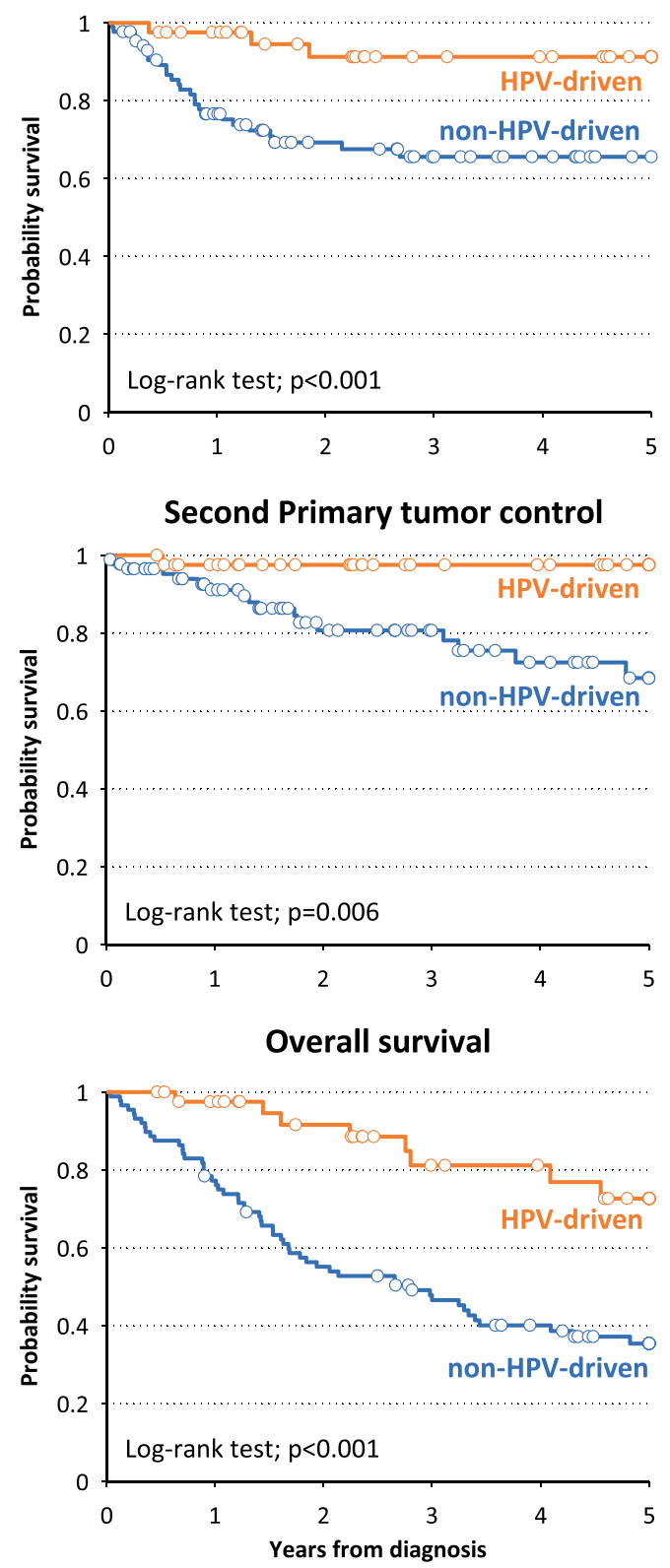

Figure 3. Kaplan Meier estimates of survival outcomes in HPV-driven and non-HPV-driven oropharyngeal cancers. Distinct panels show different clinical outcomes.

\section{Discussion}

The incidence of HPV-driven OPC in North-Eastern Italy is lower than in Northern Europe and North America ${ }^{7}$, but the results of this study demonstrate that in this area it has significantly increased over the last two decades (raising from $17 \%$ in $2000-2006$ to $46 \%$ in $2013-2018$ ), thus reinforcing our previous observations ${ }^{17}$. Also in a previous Italian cancer registry-based study covering the period $1988-2012^{18}$, we showed a rising trend of HNSCC carcinomas potentially related to HPV (i.e. arising in the oropharynx). Altogether these observations indicate that a real increase of HPV-driven OPC cases is occurring in Italy. Moreover, our data highlight other two interesting aspects. First, the increase in HPV-driven cancers is more marked in females than males; second, $\mathrm{HPV}$-driven OPC cases are no longer a disease restricted to the younger ages.

Differences by gender of HPV-driven OPC prevalence and time trends, with differential geographical distributions, have been already reported, and related to environmental risk factors and behavioural habits ${ }^{2,13}$. According to Combes et al. ${ }^{19}$, the male/female prevalence ratio we observed ( 0.49$)$ is consistent with an excess of tobacco and alcohol related OPC in men compared to women in our geographic area. In Italy, both smoking and alcohol consumption are more prevalent among males than females: $25.5 \%$ versus $17 \%$ are current smokers, and $78.4 \%$ versus $46.1 \%$ are drinkers, respectively; moreover, alcohol drinkers are most frequent among current smokers $(\mathrm{OR}=2.17)$, and alcohol consumption is more frequent in Northern than in Southern regions ${ }^{20,21}$. In relation to 
the temporal variations of HPV-driven OPC cases, an estimated higher prevalence in women than in men was reported and shown to be statistically significant in all European regions (except Northern Europe) ${ }^{2}$. In Italy, the age-adjusted incidence trends of SCC arising from HPV-related sites registered (10 cancer registries, for a total of 28295 HNSCC cases) during the 1988-2012 period $^{18}$ were stable in males and increased in women.

In line with recent reports ${ }^{22}$, we recorded HPV-driven cases with similar frequency in the different age groups. Indeed, while HPV-driven OPC was initially described as a new entity affecting mainly men aged 40 to 59 years ${ }^{23}$, in recent years it is becoming more common in older patients, and this change has been related to birth cohort effects $^{24}$. The increase in the proportion of HPV-driven OPC cases among elderly patients bears the clinical challenge of treating patients with comorbidities for whom the survival advantage of HPV pathogenesis might be attenuated, and portend the need to include patients over 70 into the clinical trials assessing therapeutic and post-treatment surveillance protocols.

In comparison to non-HPV-driven cases, patients with HPV-driven OPC experienced significantly better survival outcomes, with the exception of distant control that was similar in the two groups. The HPV status of the tumor was established by the presence of HPV DNA sequences plus at least one additional marker, usually p16 overexpression, in order to identify truly HPV-driven tumors ${ }^{15}$. The presence of a single marker, i.e. HPV DNA positivity or p16 overexpression, does not always reflect a pathogenetic role of HPV. The detection of HPV-DNA and mRNA sequences or of HPV-DNA at high viral load has been shown to reliably identify transcriptionally active infections ${ }^{15,25}$. Moreover, since the HPV causality bears a prognostic significance, it would be important to define and standardize the laboratory protocol for the correct identification of HPV-driven OPC, also because many HPV-DNA detection assays, highly different in technical and analytical characteristics, are commercially available. Indeed, the clinical outcome reported for patients with discordant results for HPV-DNA and p16 is most often similar to non-HPV-driven cases ${ }^{26,27}$. The eighth edition of the AJCC/UICC (American Joint Committee on Cancer / Union for International Cancer Control) TNM staging system demonstrated a better prognostic capacity than the seventh edition for HPV-associated OPC, but confirms the concerns previously expressed ${ }^{28}$ on using p16 overexpression as a stand-alone test to define an OPC as HPV-driven. Indeed, in line with data of other studies $^{29}$, in our study population the five patients with HPV-DNA-negative/p16-positive OPC showed an unfavorable clinical outcome, with local and regional, but not distant, disease progression (Supplementary Table 1), at variance with the observation by Rasmussen et al..$^{30}$ of higher risk of M-site recurrence; the lower number of cases might explain this difference. Thus, we strongly recommend to use the double positivity for HPV-DNA/p $16^{\text {INK4a }}$ to estimate the burden of HPV-driven OPSCC, obtain more precise prognostic information, and select patients in clinical trials exploring treatment de-intensification strategies for HPV-driven OPC.

HPV genotyping identified type 16 in $88 \%$ of cases, and types 33,58 and 18 in the remaining $12 \%$, a distribution similar to that recently reported in Eastern Denmark ${ }^{14}$. Interestingly, HPV33 was identified in 3 cases (7\%), and non-16 types were found in older patients; similarly to what observed for cervical carcinoma, these observations confirm HPV33 as a highly oncogenic type ${ }^{31}$, and the incidence at younger age of HPV16-induced tumors ${ }^{32}$. Among the high-risk types, HPV16 is the most carcinogenic; in the cervix HPV16 infections are characterized by a much higher degree of developing high-grade disease within a shorter period of time than other high-risk types $^{32}$. Whereas a poorer OS was observed in Norwegian patients with OPC associated with non-HPV16 types ${ }^{33}$, no differences in relation to HPV type emerged among our cases, but we analyzed a lower number of cases.

Strengths of our study are the use of two biomarkers for HPV-driven determination and the long period of patients' enrollment and follow-up. A limitation is the relatively small number of patients included in our cohort.

In conclusion, we have observed an age-independent increasing prevalence of HPV-driven OPC over the last two decades also in North-East Italy. Patients with HPV-driven tumors defined by HPV-DNA positivity and additional markers (p16 and/or high viral load) showed an improved prognosis. Conversely, p16 positive/HPV-DNA negative patients had a worse outcome, underlying the importance to use additional markers to define the etiological role of HPV in these malignancies. Similar to cervical cancer, infections by non-HPV16 oncogenic types were restricted to older OPC cases. Systematic review and meta-analysis are required to investigate the prognostic impact of non-HPV16 oncogenic types in patients with OPC.

\section{Methods}

Aim, design and setting of the study. Aims of the study are to evaluate the temporal trend of HPVdriven OPCs in North-East Italy over a 18-year period, and to compare the clinical outcome of HPV-driven and chemically induced cases, also in relation to the HPV type. The OPC cases included in the present analysis represent a subset of a multicenter ongoing prospective cohort study on HPV involvement and prognostic biomarkers in head and neck squamous cell carcinoma (HNSCC) patients initiated in the year 2000. Patients were treated at 3 Ear, Nose, and Throat (ENT) Units located in North-East Italy (i.e., Treviso Regional Hospital, Hospital of Mirano, and Trieste Cattinara Hospital).

Patients and tissue samples. All the available records of patients with OPC managed with curative intent from September 2000 to August 2018 were reviewed. Treatment planning was discussed by a multidisciplinary tumor board in order to decide the appropriate strategy, and management decisions were not guided by knowledge of HPV status. All patients underwent a regular follow-up until death or 31 July 2019, except one who at this date was still under treatment. Clinical, epidemiological, socio-demographic and behavioral data were also retrieved (gender, age, year of diagnosis, cancer subsite, TNM stage, histological grading when applicable (HPV-driven SCC is not graded), tobacco smoking, alcohol drinking). Histological diagnoses were determined by the local pathologists. All tumors were classified according to the WHO (World Health Organization) $4^{\text {th }}$ Edition and staged according to the AJCC $7^{\text {th }}$ Edition classification with reclassification also according to the $8^{\text {th }}$ Edition, that introduces a separate staging algorithm for HPV-driven $\mathrm{OPC}^{34}$. 
The whole study was approved by the ethic committee for clinical experimentation (CEP) of Treviso (Ethic votes: 345/AULSS9 and 421/AULSS9). All patients signed an informed consent. Data on 63 patients have been included in previously published reports ${ }^{17,35,36}$. We confirm that all experiments were performed in accordance with relevant guidelines and regulations.

Fresh frozen (FF) and/or formalin-fixed paraffin-embedded (FFPE) specimens of the neoplastic lesions (primary tumor from all the enrolled patients, and recurrent tumors from HPV-driven cases) were collected.

DNA was extracted by the phenol-chloroform (PC9) method [as previously described by Baboci et al. ${ }^{17}$ or by the QIAamp DNA kit (Qiagen), according to the manufacturer's instructions.

HPV analyses. Search and typing of HPV DNA sequences were performed by PCR using MY09/MY11 primers and restriction fragment length polymorphism (RFLP) analysis of the amplified products, as previously described ${ }^{17}$. Quantitative real-time PCR (qPCR) was performed on HPV16-positive samples by using primers and probe specific for HPV16-E6, according to Peitsaro et al. ${ }^{37}$; two standard curves were obtained by amplification of 10 -fold serial dilutions of full-length HPV16 genome (Clonit, Alfa Wassermann; $10^{2}$ to $10^{6}$ copies/ $\mu$ l) and the beta-globin gene (Roche; 2 to $200 \mathrm{ng}$ ). The E6 copy number and the amount of beta-globin were calculated; the viral load was expressed as HPV16 copies/cell.

Immunohistochemistry for $\mathrm{p} 16^{\mathrm{INK} 4 \mathrm{~A}}$ protein expression. The expression of $\mathrm{p} 16^{\mathrm{INK} 4 \mathrm{a}}$ protein (indicated as p16) was performed on FFPE sections by immunostaining using the primary antibody CINtec for V-kit (MTM laboratories, Heidelberg, Germany), as previously described ${ }^{11}$, or the BD Pharmingen IHC Detection kit, according to the manufacturer's instructions. The expression results were scored as positive by using a $70 \%$ cut-point and considering nuclear and cytoplasmic stain distribution.

Statistical analyses. A tumor was defined as HPV-driven by using at least two different biomarkers, usually HPV-DNA positivity and $16^{\mathrm{INK} 4 \mathrm{~A}}$ overexpression; alternatively, positivity for HPV-DNA and a different biomarker (HPV16 mRNA, anti-E6/E7 antibodies, HPV16 high viral load, HPV16/18 E6 Oncoprotein) were used, as previously described ${ }^{17}$.

To facilitate statistical analysis due to the relatively small number of patients, clinical and socio-demographic data were divided into categories. HPV-driven and non-HPV-driven cancers were compared for each variable. Cochran-Mantel-Haenszel and Fisher exact tests were used, as appropriate. Similarly, median value of HPV16 copies for HPV16 positive cancers were compared for each variable, using Kruskall-Wallis test. For each patient, person-time at risk was calculated from diagnosis to event of interest or last available follow-up, whichever came first. Follow-up was truncated at 5 years. Event was defined as cancer recurrence at the UADT (Upper Aero Digestive Tract) site for mucosal control; neck lymph node failure for regional control; local cancer recurrence or regional failure for loco-regional control; distant metastasis for distant control; second primary tumor (SPT) for SPT survival; mucosal, regional or distant recurrence or death for progression-free survival (PFS); death for overall survival (OS). Survival probabilities were estimated according to Kaplan-Meier method and differences according to strata were tested through log-rank test. Progression-free survival and overall survival in the different categories identified by the clinical and socio-demographic data were evaluated by a multivariate model using Cox proportional hazards regression, adjusted for gender, age, year of diagnosis, TNM stage ( $8^{\text {th }}$ ed.) and alcohol drinking. A similar multivariate model was generated in order to investigate survival outcomes (mucosal control, regional control, loco-regional control, distant control, second primary tumors [SPT] control, progression-free survival, overall survival) in HPV-driven tumors vs. non-HPV-driven tumors, adjusting for gender, age and year of diagnosis to obtain crude estimates, and also for T status, $\mathrm{N}$ status and alcohol drinking for adjusted estimates.

Ethics approval and consent to participate. The whole study was approved by the ethic committee for clinical experimentation (CEP) of Treviso (Ethic votes: 345/AULSS9 and 421/AULSS9). All patients signed an informed consent.

\section{Data availability}

The data that support the findings of this study are available from the corresponding author upon reasonable request.

Received: 10 February 2020; Accepted: 13 May 2020;

Published online: 09 June 2020

\section{References}

1. Hashibe, M. et al. Alcohol drinking in never users of tobacco, cigarette smoking in never drinkers, and the risk of head and neck cancer: pooled analysis in the International Head and Neck Cancer Epidemiology Consortium. J. Natl. Cancer Inst. 99, 777-789, https://doi.org/10.1093/jnci/djk179 (2007).

2. Castellsague, X. et al. HPV involvement in head and neck cancers: comprehensive assessment of biomarkers in 3680 patients. J. Natl. Cancer Inst 108, djv403, https://doi.org/10.1093/jnci/djv403 (2016).

3. Ang, K. K. et al. Human papillomavirus and survival of patients with oropharyngeal cancer. N. Engl. J. Med. 363, 24-35, https://doi. org/10.1056/NEJMoa0912217 (2010).

4. Gillison, M. L. et al. Tobacco smoking and increased risk of death and progression for patients with p16-positive and p16-negative oropharyngeal cancer. J Clin. Oncol. 30, 2102-2111, https://doi.org/10.1200/JCO.2011.38.4099 (2012).

5. Mirghani, H. et al. Smoking impact on HPV driven head and neck cancer's oncological outcomes? Oral. Oncol. 82, 131-137, https:// doi.org/10.1016/j.oraloncology.2018.05.007 (2018).

6. Mirghani, H., Lang Kuhs, K. A. \& Waterboer, T. Biomarkers of early identification of recurrences in HPV-driven oropharyngeal cancer. Oral. Oncol. 82, 108-114, https://doi.org/10.1016/j.oraloncology.2018.05.015 (2018). 
7. de Martel, C., Plummer, M., Vignat, J. \& Franceschi, S. Worldwide burden of cancer attributable to HPV by site, country and HPV type. Int. J. Cancer 141, 664-670, https://doi.org/10.1002/ijc.30716 (2017).

8. Ndiaye, C. et al. HPV DNA, E6/E7 mRNA, and p16INK4a detection in head and neck cancers: a systematic review and metaanalysis. Lancet Oncol. 15, 1319-1331, https://doi.org/10.1016/S1470-2045(14)70471-1 (2014).

9. Fallai, C. et al. Oropharyngeal squamous cell carcinoma treated with radiotherapy or radiochemotherapy: prognostic role of TP53 and HPV status. Int. J. Radiation Oncology Biol. Phys. 75, 1053-1059 (2009).

10. Bussu, F. et al. Human Papillomavirus (HPV) infection in squamous cell carcinomas arising from the oropharynx: detection of HPV DNA and p16 immunohistochemistry as diagnostic and prognostic indicators - A pilot study. Int. J. Radiation Oncology Biol. Phys. 89, 1115-1120 (2014)

11. Rollo, F. et al. Evaluation of the Anyplex II HPV28 assay in the detection of huuman papillomavirus in archival samples of oropharyngeal carcinomas. Arch. Pathol. Lab. Med. 144, 620-625,https://doi.org/10.5858/arpa.2019-0199-OA (2020).

12. Badaracco, G. et al. Molecular analyses and prognostic relevance of HPV in head and neck tumours. Oncology Reports 17, 931-939 (2007).

13. Chaturvedi, A. K. et al. Worldwide trends in incidence rates for oral cavity and oropharyngeal cancers. J. Clin. Oncol. 31, 4550-4559, https://doi.org/10.1200/JCO.2013.50.3870 (2013).

14. Carlander, A. F. et al. Continuing rise in oropharyngeal cancer in a high HPV prevalence area: a Danish population-based study from 2011 to 2014. Eur. J. Cancer 70, 75-82, https://doi.org/10.1016/j.ejca.2016.10.015 (2017).

15. Boscolo-Rizzo, P., Pawlita, M. \& Holzinger, D. From HPV-positive towards HPV-driven oropharyngeal squamous cell carcinomas. Cancer Treat. Rev. 42, 24-29, https://doi.org/10.1016/j.ctrv.2015.10.009 (2016).

16. Oosthuizen, J. C. \& Doody, J. De-intensified treatment in human papillomavirus-positive oropharyngeal cancer. Lancet 393(10166), 5-7, https://doi.org/10.1016/S0140-6736(18)23930-1 (2019).

17. Baboci, L. et al. Low prevalence of HPV-driven head and neck squamous cell carcinoma in North-East Italy. Papillomavirus Res. 2, 133-140, https://doi.org/10.1016/j.pvr.2016.07.002 (2016).

18. Boscolo-Rizzo, P. et al. The evolution of the epidemiological landscape of head and neck cancer in Italy: is there evidence for an increase in the incidence of potentially HPV-related carcinomas? PLoS ONE 13, e192621, https://doi.org/10.1371/journal. pone.0192621 (2018).

19. Combes, J. D., Chen, A. A. \& Franceschi, S. Prevalence of human papillomavirus in cancer of the oropharynx by gender. Cancer Epidemiol. Biomarkers Prev. 23, 2954-2958, https://doi.org/10.1158/1055.9965 (2014).

20. Lugo, A. et al. Smoking in Italy 2013-2014, with a focus on the young. Tumori 101, 529-534, https://doi.org/10.5301/tj.5000311 (2015).

21. Asciutto, R. et al. The particular story of Italians' relation with alcohol: trends in individuals' consumption by age and beverage type. Alcohol and Alcoholism 51, 347-353, https://doi.org/10.1093/alcalc/agv121 (2016).

22. Rettig, E. M. et al. Oropharyngeal cancer is no longer a disease of younger patients and the prognostic advantage of Human Papillomavirus is attenuated among older patients: analysis of the National Cancer Database. Oral Oncol. 83, 147-153, https://doi. org/10.1016/j.oraloncology.2018.06.013 (2018).

23. Gillison, M. L. et al. Evidence for a causal association between human papillomavirus and a subset of head and neck cancers. J. Natl. Cancer Inst. 92, 709-720 (2000).

24. Chaturvedi, A. K. \& Zumsteg, Z. S. A snapshot of the evolving epidemiology of oropharynx cancers. Cancer 124, 2893-2896, https:// doi.org/10.1002/cncr.31383 (2015).

25. Holzinger, D. et al. Viral RNA patterns and high viral load reliably define oropharynx carcinomas with active HPV16 involvement. Cancer Res. 72, 4993-5003, https://doi.org/10.1158/0008-5472.CAN-11-3934 (2012).

26. Mena, M. et al. Double positivity for HPV-DNA/p16INK4A is the biomarker with strongest diagnostic accuracy and prognostic value for human papillomavirus related oropharyngeal cancer patients. Oral Oncol. 78, 137-144, https://doi.org/10.1016/j. oraloncology.2018.01.010 (2018).

27. Nauta, I. H. et al. Evaluation of the eighth TNM classification on p16-positive oropharyngeal squamous cell carcinomas in the Netherlands and the importance of additional HPV testing. Ann. Oncol. 29, 1273-1279, https://doi.org/10.1093/annonc/mdy060 (2018).

28. Boscolo-Rizzo, P. \& Dietz, A. The AJCC/UICC eighth edition for staging head and neck cancers: is it wise to de-escalate treatment regimens in p16-positive oropharyngeal cancer patients? Int. J. Cancer 141, 1490-1491, https://doi.org/10.1002/ijc.30837 (2017).

29. Prigge, E. S., Arbyn, M., von Knebel Doeberitz, M. \& Reuschenbach, M. Diagnostic accuracy of p16INK4a immunohistochemistry in oropharyngeal squamous cell carcinomas: a systematic review and meta-analysis. Int. J. Cancer 140, 1186-1198, https://doi. org/10.1002/ijc.30516 (2017).

30. Rasmussen, J. H. et al. Risk profiling based on p16 and HPV DNA more accurately predicts location of disease relapse in patients with oropharyngeal sqaumous cell carcinoma. Ann. Oncol. 30, 629-636, https://doi.org/10.1093/annonc/mdz010 (2019).

31. Del Mistro, A. et al. HPV genotyping for the cross-sectional and longitudinal probability of developing CIN2. Int. J. Cancer 143, 333-342, https://doi.org/10.1002/ijc.31326 (2018).

32. de Sanjose, S. et al. Human papillomavirus genotype attribution in invasive cervical cancer: a retrospective cross-sectional worldwide study. Lancet Oncol. 11, 1048-1056, https://doi.org/10.1016/S1470-2045(10)70230-8 (2010).

33. Fossum, G. H., Lie, A. K., Jebsen, P., Sandlie, L. E. \& Mork, J. Human papillomavirus in oropharyngeal squamous cell carcinoma in South-Eastern Norway: prevalence, genotype, and survival. Eur. Arch. Otorhinolaryngol. 274, 4003-4010, https://doi.org/10.1007/ s00405-017-4748-8 (2017).

34. Lydiatt, W. M. et al. Head and neck cancers - major changes in the American Joint Committee on Cancer eighth edition cancer staging manual. CA Cancer J. Clin. 67, 122-137, https://doi.org/10.3322/caac.21389 (2017).

35. Boscolo-Rizzo, P. et al. HPV-16 E6 L83V variant in squamous cell carcinomas of the upper aerodigestive tract. J. Cancer Res. Clin. Oncol. 135, 559-566, https://doi.org/10.1007/s00432-008-04090-3 (2009).

36. Baboci, L. et al. Evidence of the causal role of human papilloma virus type 58 in an oropharyngeal carcinoma. Virol. J. 10, 334 (2013). doi:10.1016/

37. Peitsaro, P., Johansson, B. \& Syrjänen, S. Integrated human papillomavirus type 16 is frequently found in cervical cancer precursors as demonstrated by a novel quantitative real-time PCR technique. J. Clin. Microbiol. 40, 886-891, https://doi.org/10.1128/ jcm.40.3.886-891.2002 (2002)

\section{Acknowledgements}

We appreciate the excellent technical assistance of R. Trevisan. This work was supported by Lega Italiana per la Lotta contro i Tumori (LILT). The funders had no role in study design, data collection, data analysis, data interpretation or writing of the report, nor in the decision to submit for publication.

\section{Author contributions}

A.D.M. and P.B.R: guarantors of the integrity of the study. A.D.M., P.B.R., G.T. and M.C.d.M.: concept and design. A.D.M., P.B.R., S.R., H.F., A.M., N.F., S.G., G.S., G.T. and M.C.d.M.: data acquisition and analyses. A.D.M., P.B.R. and S.R.: interpretation of data. J.P.: statistical analyses. A.D.M. and P.B.R: manuscript drafting. A.D.M., P.B.R., P.N., J.P., S.R., H.F., A.M., N.F., S.G., G.S., G.T. and M.C.d.M.: manuscript review. 


\section{Competing interests}

The authors declare no competing interests.

\section{Additional information}

Supplementary information is available for this paper at https://doi.org/10.1038/s41598-020-66323-z.

Correspondence and requests for materials should be addressed to A.D.M.

Reprints and permissions information is available at www.nature.com/reprints.

Publisher's note Springer Nature remains neutral with regard to jurisdictional claims in published maps and institutional affiliations.

(c) (i) Open Access This article is licensed under a Creative Commons Attribution 4.0 International License, which permits use, sharing, adaptation, distribution and reproduction in any medium or format, as long as you give appropriate credit to the original author(s) and the source, provide a link to the Creative Commons license, and indicate if changes were made. The images or other third party material in this article are included in the article's Creative Commons license, unless indicated otherwise in a credit line to the material. If material is not included in the article's Creative Commons license and your intended use is not permitted by statutory regulation or exceeds the permitted use, you will need to obtain permission directly from the copyright holder. To view a copy of this license, visit http://creativecommons.org/licenses/by/4.0/.

(C) The Author(s) 2020 